\title{
MCP-1 and MIP-1A Gene Polymorphisms in Japanese Patients with Sarcoidosis
}

\author{
Toshinori TaKada, Eiichi Suzuki, Kazuaki Morohashi, Kentaro OMORI and Fumitake Gejyo
}

\begin{abstract}
Objectives Monocyte chemoattractant protein (MCP)1 and macrophage inflammatory protein (MIP)- $1 \alpha$ exhibit chemotactic activity toward macrophages/monocytes and induce the production of inflammatory cytokines affecting granuloma formation. Recently, a single nucleotide polymorphism (SNP) in the MCP-1 distal regulatory region and a dinucleotide repeat in the MIP-1A gene promoter region were identified. We investigated the relationships between the polymorphisms and susceptibility to sarcoidosis, clinical manifestations, and BALF findings of sarcoidosis.

Methods The polymorphisms of the MCP-1 and MIP$1 \mathrm{~A}$ genes in 118 patients with sarcoidosis and 145 healthy control subjects were examined. The MCP-1 polymorphism was genotyped by a PCR-restriction fragment length polymorphism method and the MIP-1A genotype was determined using PCR.

Results No significant difference in the genotype distribution or in the allele frequency between the patients and control subjects was observed. We found no relationship between the polymorphisms and the serum ACE level, organ involvement, roentgenographic stages, or deterioration in chest radiographs during the follow-up. A significant difference in the absolute counts of AMs in BALF of 51 patients among the genotypes of the MCP-1 gene was found $(p=0.048)$. The AM counts in BALF of the $G / A$ and $G / G$ genotypes were significantly increased compared with that of the $\mathrm{A} /$ A genotype $(\mathbf{p}<\mathbf{0 . 0 5})$.

Conclusion The polymorphisms of the MCP-1 and MIP$1 \mathrm{~A}$ genes do not play a substantial role in genetic predisposition for sarcoidosis or in clinical manifestations of sarcoidosis in this Japanese population. The MCP-1 SNP might be related to the recruitment of monocytes/macrophages to the alveolar spaces in sarcoidosis.

(Internal Medicine 41: 813-818, 2002)
\end{abstract}

Key words: genetic susceptibility, microsatellite, PCR-RFLP, single nucleotide polymorphism

\section{Introduction}

Sarcoidosis is a systemic granulomatous disorder of unknown etiology involving multiple organs $(1,2)$. Sarcoid granuloma typically shows a center of epithelioid cells surrounded by $\mathrm{CD} 4^{+}$lymphocytes, some $\mathrm{CD} 8^{+}$lymphocytes, giant cells, and mature macrophages. In the affected organs, activated $\mathrm{T}$ cells and macrophages release a number of cytokines that provide the stimulus for progress toward the granuloma formation and, in some cases, to fibrosis. The recruitment of macrophages and $\mathrm{T}$ cells into the affected organ is thought to be an important step in the development of sarcoidosis.

Monocyte chemoattractant protein (MCP)-1 and macrophage inflammatory protein (MIP)- $1 \alpha$ are members of the C-C chemokine supergene family $(3,4)$. MCP-1 is a monocyte-specific chemotactic factor produced by a wide variety of cell types, including monocytes, fibroblasts, vascular endothelial cells, and smooth muscle cells. MIP- $1 \alpha$ is produced by appropriately stimulated T cells, alveolar and peritoneal macrophages, neutrophils, monocytes, airway epithelial cells, and fibroblasts, and has been shown to activate mast cells and basophils to be chemotactic for $T$ cells and monocytes. Both chemokines contribute to acute and cellular immune tissue responses via recruitment and activation of macrophages and $\mathrm{T}$ cells inducing the production of inflammatory cytokines which affect granuloma formation (5-8). In sarcoidosis, the elevation of the MCP-1 and MIP- $1 \alpha$ levels in bronchoalveolar lavage fluid (BALF) and the up-regulated expression of these chemokines in macrophages in the affected organ have been shown $(9,10)$.

The human MCP-1 gene transcript appears to be under the control of two distinct areas of the $5^{\prime}$-flanking region of the gene. Recently, two single nucleotide polymorphisms (SNPs) in the MCP-1 distal regulatory region were identified and the SNP at position $-2,518$ was found to affect the transcriptional activity of the regulatory region, and monocyte MCP-1 production (11). As for the MIP-1A gene, a biallelic dinucleotide microsatellite repeat was recently identified (12). The repeat occurs within the promoter region, making it an ideal marker for association and linkage studies in inflammatory diseases.

In the present study, we investigated the MCP-1 and MIP-

From the Division of Respiratory Medicine, Graduate School of Medical and Dental Sciences, Niigata University, Niigata

Received for publication January 7, 2002; Accepted for publication June 19, 2002

Reprint requests should be addressed to Dr. Toshinori Takada, the Division of Respiratory Medicine, Graduate School of Medical and Dental Sciences, Niigata University, 1-757 Asahimachi-dori, Niigata 951-8510 
1A polymorphisms to clarify whether these polymorphisms are associated with susceptibility to sarcoidosis, clinical manifestations, and BALF findings of sarcoidosis in a Japanese population.

\section{Methods}

\section{Study Population}

One hundred eighteen Japanese subjects with sarcoidosis were recruited from the clinic at the Niigata University Hospital. Sarcoidosis was diagnosed on the basis of the typical clinical features and the presence of epithelioid cell granulomas in biopsy specimens from the lung, skin, or lymph nodes. Fortyfour of the cases were men and 74 were women. The average age of the patients at diagnosis was 45.1 years with a range between 19 and 74 years. Regarding the roentgenographic stage of the patients at the first visit to our hospital, all but 10 had chest X-ray evidence of sarcoidosis, 59 with stage I, 41 with stage II, and eight with stage III disease.
As healthy controls, 145 unrelated healthy Japanese subjects were selected. They consisted of 84 men and 61 women with a mean age of 40.9 years and a range between 21 and 70 years. They did not have any abnormalities based on physical examination, chest radiography, electrocardiogram (ECG), urinalysis, and routine laboratory blood testing. None were receiving medication at the time of the evaluation. All of the subjects in the study gave written informed consent for enrollment in the study and this study was approved by the Committee of Ethics, Niigata University.

\section{Determination of the MCP-1 and MIP-1A genotypes}

DNA was extracted from peripheral leukocytes with standard techniques. The polymerase chain reaction (PCR)-restriction fragment length polymorphism method was performed as described by Rovin et al (11) for MCP-1 genotyping. Specific oligonucleotide primers (5'-CCG AGA TGT TCC CAG CAC AG-3', and 5'-CTG CTT TGC TTG TGC CTC TT-3') were utilized with PCR to amplify a 930 bp segment of the MCP-1



A

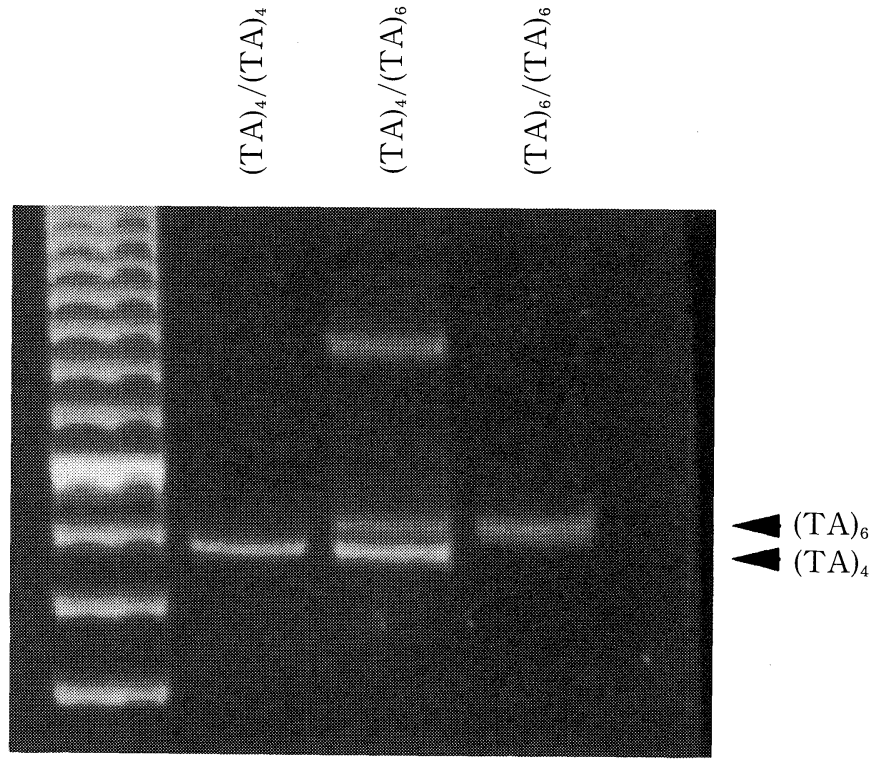

$\mathrm{B}$

Figure 1. Determination of MCP-1 and MIP-1A genotypes. The left lane of each panel contains markers. Panel $A$ shows part of a representative $1 \%$ agarose gel stained with ethidium bromide and photographed under ultraviolet transillumination after PCR and digestion by Pvu II for MCP-1 genotyping. The upper band of 930 bp is the G allele and the lower band of $708 \mathrm{bp}$ is the $\mathrm{G}$ allele (arrowheads). The A/A type is shown as a single upper band, the G/G type as a single lower band, and the G/A type as a double band. Panel $B$ shows part of a representative $12 \%$ polyacrylamide gel stained with ethidium bromide and photographed under ultraviolet transillumination after PCR for MIP-1A genotyping. The upper band is the (TA) $)_{6}$ allele and the lower band is the (TA) $)_{4}$ allele (arrowheads). The (TA) $)_{6} /(\mathrm{TA})_{6}$ type is shown as a single upper band, the (TA $)_{6} /(\mathrm{TA})_{4}$ type as a single lower band, and the (TA $)_{6} /(\mathrm{TA})_{4}$ type as a double band. 
5 '-flanking region between nucleotide $-1,817$ and $-2,746$ relative to the major transcriptional start site defined by Ueda et al (13). PCR was performed using denaturation at $94^{\circ} \mathrm{C}$ for 3 minutes, followed by 35 cycles at $94^{\circ} \mathrm{C}$ for 30 seconds, $60^{\circ} \mathrm{C}$ for 30 seconds, and $72^{\circ} \mathrm{C}$ for 30 seconds, and a final extension at $72^{\circ} \mathrm{C}$ for 3 minutes (DNA Thermal Cycler 9600; Perkin Elmer-Cetus, Norwalk, CT). The PCR products were digested with $2.0 \mathrm{U}$ of Pvu II (Takara-Shuzo, Kyoto) at $37^{\circ} \mathrm{C}$ for 2 hours, and run on a $1 \%$ ethidium bromide-agarose gel. Pvu II digested the 930 bp DNA segment from G/G homozygous individuals into 708 and 222 bp fragments. DNA from A/A homozygous individuals was not cut with Pvu II. DNA from G/A hetorozygous individuals showed the expected fragments at 930, 708, and 222 bp (Fig. 1A).

The PCR for MIP-1A genotyping was performed using the following primers: $5^{\prime}$-TGT ATT TTT TTC CAT GCT TAG GGT TG-3', and 5'-TCA GTG GTT AAA AAA AGC AAG ATA CGA-3'. PCR cycles were as follows: $94^{\circ} \mathrm{C}$ for 3 minutes followed by 35 cycles each of $94^{\circ} \mathrm{C}$ for 30 seconds, $53^{\circ} \mathrm{C}$ for 30 seconds, and $72^{\circ} \mathrm{C}$ for 30 seconds. A final extension step was carried out at $72^{\circ} \mathrm{C}$ for 3 minutes. The PCR products were visualized on a $12 \%$ polyacrylamide gel (acrylamide: bisacrylamide 19: 1) containing 10\% glycerol stained with ethidium bromide (Fig. 1B). Samples that exhibited a single band were sequenced using the BigDye terminator cycle sequencing kit (PE; Applied Biosystems, Foster City, CA). Sequencing revealed a biallelic dinucleotide microsatellite repeat starting at position (-906) relative to the transcription site as described by Al-Sharif et al (12).

\section{Bronchoalveolar lavage}

Bronchoscopy with BAL was performed on 51 patients with sarcoidosis with the informed consent of the patient as part of the routine clinical management of sarcoidosis as previously described (14). Briefly, four 50-ml aliquots of $0.9 \% \mathrm{NaCl}$ were instilled into the middle lobe. Each aliquot of infused fluid was immediately aspirated gently. The recovered BALF was strained through three layers of gauze and kept on ice. Total cell counts were made using a hemocytometer and cell differentials were determined after cytocentrifugation and May-Giemsa staining.

\section{Statistical analysis}

The allele ratios and genotype distributions in sarcoidosis patients and control subjects, roentgenographic stages, and organ involvement among the three genotypes were analyzed with the chi-square test. The Fisher's exact test was also applied for comparison of small populations with expected values of less than five. The comparison of the serum level of ACE, and the percentage and the absolute count of alveolar macrophages (AMs) and lymphocytes in BALF among the genotypes was tested with the Kruskal-Wallis rank test. The Mann-Whitney U-test was applied for comparison of the serum ACE level and the percentage and absolute count of BALF cells between the genotypes. A p value $<0.05$ was considered significant.

\section{Results}

The allele frequencies and genotypes for the MCP-1 and MIP-1A polymorphisms are summarized in Table 1. As for MCP-1 genotypes, of the 118 sarcoidosis patients, 15 had the A/A genotype (12.7\%), 57 the G/A type (48.3\%), and $46 \mathrm{G} / \mathrm{G}$ type $(39.0 \%)$. The frequency of A allele was $36.9 \%$. Of the 145 healthy control subjects, 9 were type A/A (6.2\%), 66 were $\mathrm{G} / \mathrm{A}(45.5 \%)$, and 70 were $\mathrm{G} / \mathrm{G}(48.3 \%)$. The frequency of A allele was $29.0 \%$. No significant difference in the genotype distribution or in the allele frequency between the sarcoidosis patients and healthy control subjects was observed. As for MIP1A genotype of the 116 sarcoidosis patients, 15 had the (TA) ${ }_{4} /$ (TA $)_{4}$ genotype $(12.9 \%), 40$ the $(\mathrm{TA})_{4} /(\mathrm{TA})_{6}$ type $(34.5 \%)$, and $61(\mathrm{TA})_{6} /(\mathrm{TA})_{6}$ type $(52.6 \%)$. The frequency of $(\mathrm{TA})_{4}$ allele was $30.2 \%$. Of the 145 healthy control subjects, 12 were type $(\mathrm{TA})_{4} /(\mathrm{TA})_{4}(8.3 \%), 62$ were $(\mathrm{TA})_{4} /(\mathrm{TA})_{6}(42.7 \%)$, and 71 were $(\mathrm{TA})_{6} /(\mathrm{TA})_{6}(49.0 \%)$. The frequency of $(\mathrm{TA})_{4}$ allele was $29.7 \%$. No significant difference in the genotype distribution or in the allele frequency between the sarcoidosis patients and healthy control subjects was observed.

We then examined the relationship with the serum ACE level, organ involvement, roentgenographic stages, and deterioration in chest radiographs during the follow-up (Table 2). Cases of eye $(n=85)$, skin $(n=12)$, heart $(n=12)$ and involvement of three or more organs $(n=25)$ were examined. We found no significant correlation with the MCP-1 or MIP-1A genotype.

Next, we reviewed the BAL findings in 51 of the 118 patients who underwent bronchoscopy with BAL as part of the routine clinical management of sarcoidosis. The other $67 \mathrm{pa}-$

Table 1. Genotype Distribution in Sarcoidosis and Controls

\begin{tabular}{|c|c|c|c|}
\hline MCP-1 & $\begin{array}{l}\text { Sarcoidosis } \\
\quad(n=118)\end{array}$ & $\begin{array}{l}\text { Control subjects } \\
\qquad(n=145)\end{array}$ & $\mathrm{p}$ Value $^{\dagger}$ \\
\hline \multicolumn{4}{|c|}{ Alleles, no. of alleles (\%) } \\
\hline A & $87(36.9)$ & $84(29.0)$ & \multirow[t]{2}{*}{0.0544} \\
\hline $\mathrm{G}$ & $149(63.1)$ & $206(71.0)$ & \\
\hline \multicolumn{4}{|c|}{ Genotype, no. of subjects (\%) } \\
\hline $\mathrm{A} / \mathrm{A}$ & $15(12.7)$ & $9(6.2)$ & \multirow[t]{3}{*}{0.1109} \\
\hline $\mathrm{G} / \mathrm{A}$ & $57(48.3)$ & $66(45.5)$ & \\
\hline $\mathrm{G} / \mathrm{G}$ & $46(39.0)$ & $70(48.3)$ & \\
\hline MIP-1A & $\left(\mathrm{n}=116^{*}\right)$ & $(n=145)$ & $\mathrm{p}$ Value $^{\dagger}$ \\
\hline \multicolumn{4}{|c|}{ Alleles, no. of alleles (\%) } \\
\hline$(\mathrm{TA})_{4}$ & $70(30.2)$ & $86(29.7)$ & \multirow[t]{2}{*}{0.8979} \\
\hline$(\mathrm{TA})_{6}$ & $162(69.8)$ & $204(70.3)$ & \\
\hline \multicolumn{4}{|c|}{ Genotype, no. of subjects (\%) } \\
\hline$(\mathrm{TA})_{4} /(\mathrm{TA})_{4}$ & $15(12.9)$ & $12(8.3)$ & \multirow[t]{3}{*}{0.2663} \\
\hline$(\mathrm{TA})_{4} /(\mathrm{TA})_{6}$ & $40(34.5)$ & $62(42.7)$ & \\
\hline$(\mathrm{TA})_{6} /(\mathrm{TA})_{6}$ & $61(52.6)$ & $71(49.0)$ & \\
\hline
\end{tabular}

*In two cases, MIP-1A polymorphism could not be defined. ${ }^{\dagger}$ Cases compared with control subjects. MCP-1: Monocyte chemoattractant protein-1, MIP-1A: macrophage inflammatory protein-1A. 
tients did not undergo BAL or yield a sufficient amount of BALF to be evaluated. Nine of the 51 patients had A/A type (17.7\%), $25 \mathrm{G} / \mathrm{A}$ type $(49.0 \%)$, and $17 \mathrm{G} / \mathrm{G}$ type $(33.3 \%)$ for MCP-1 genotypes. The genetic distribution was not different from that of all the 118 patients. We tested the correlations between the genotypes and the percentage and the absolute count of AMs in BALF. Although no significant difference in the percentages of AMs was observed among the genotypes, a significant difference in the absolute count of AMs was found ( $\mathrm{p}=0.048$ ) (Fig. 2). Comparing AM counts between the genotypes, the
AM counts of the G/A and G/G genotypes were significantly higher than that of the $\mathrm{A} / \mathrm{A}$ genotype $(\mathrm{p}=0.044$ and $\mathrm{p}=0.012$, respectively) (Fig. 2B). No significant difference in the absolute count of AMs was observed between the G/A and G/G genotypes $(p=0.691)$. There was no significant relationship with the percentage or the absolute count of AMs or lymphocytes for the MIP-1 genotypes (data not shown).

Table 2. Relationship of the MCP-1 or MIP-1A Polymorphism to Serum ACE and Organ Involvement

\begin{tabular}{|c|c|c|c|c|c|c|c|c|}
\hline \multirow[b]{2}{*}{ Involved organ } & \multicolumn{3}{|c|}{ MCP-1 Genotype } & \multirow[b]{2}{*}{ p-Value } & \multicolumn{3}{|c|}{ MIP-1A Genotype } & \multirow[b]{2}{*}{ p-Value } \\
\hline & $\begin{array}{c}\mathrm{A} / \mathrm{A}(\%) \\
(\mathrm{n}=15)\end{array}$ & $\begin{array}{c}\mathrm{G} / \mathrm{A}(\%) \\
(\mathrm{n}=57)\end{array}$ & $\begin{array}{c}\mathrm{G} / \mathrm{G}(\%) \\
(\mathrm{n}=46)\end{array}$ & & $\begin{array}{l}(\mathrm{TA})_{4} /(\mathrm{TA})_{4}(\%) \\
(\mathrm{n}=15)\end{array}$ & $\begin{array}{c}(\mathrm{TA})_{4} /(\mathrm{TA})_{6}(\%) \\
(\mathrm{n}=40)\end{array}$ & $\begin{array}{c}(\mathrm{TA})_{6} /(\mathrm{TA})_{6}(\%) \\
(\mathrm{n}=61)\end{array}$ & \\
\hline Serum ACE (IU/l) & $26.7 \pm 17.0$ & $29.8 \pm 15.0$ & $26.6 \pm 10.8$ & 0.337 & $35.3 \pm 24.8$ & $26.7 \pm 10.6$ & $27.3 \pm 11.5$ & 0.593 \\
\hline Eye $\left(n=85^{*}\right)$ & $10(66.7)$ & $44(77.2)$ & $30(65.2)$ & 0.3770 & $12(80.0)$ & $30(75.0)$ & $41(67.2)$ & 0.5159 \\
\hline Skin $(n=12)$ & $2(13.3)$ & $5(8.8)$ & $5(10.9)$ & 0.8560 & $2(13.3)$ & $2(5.0)$ & $8(13.1)$ & 0.3904 \\
\hline Heart $\left(n=12^{\dagger}\right)$ & $2(13.3)$ & $4(7.0)$ & $6(13.0)$ & 0.5488 & $1(6.7)$ & $4(10.0)$ & $6(9.8)$ & 0.9232 \\
\hline $\begin{array}{l}\text { More than three } \\
\quad \text { organs }(n=25)\end{array}$ & $3(20.0)$ & $10(17.5)$ & $12(26.1)$ & 0.5692 & $3(20.0)$ & $10(25.0)$ & $12(19.7)$ & 0.8065 \\
\hline $\begin{array}{l}\text { Initial chest radiograph stage II } \\
\text { or higher }\left(n=49^{*}\right)\end{array}$ & $5(33.3)$ & $22(38.6)$ & $22(47.8)$ & 0.5046 & $5(33.3)$ & $16(40.0)$ & $27(44.2)$ & 0.7259 \\
\hline $\begin{array}{l}\text { Deterioration in chest } \\
\text { Radiograph }(\mathrm{n}=8)\end{array}$ & $0(0)$ & $3(5.3)$ & $5(10.9)$ & 0.284 & $2(13.3)$ & $1(2.5)$ & $5(8.2)$ & 0.312 \\
\hline
\end{tabular}

*In two cases, MIP-1A polymorphism could not be defined. ‘n one case, MIP-1A polymorphism could not be defined. MCP-1: Monocyte chemoattractant protein-1, MIP-1A: macrophage inflammatory protein-1A.

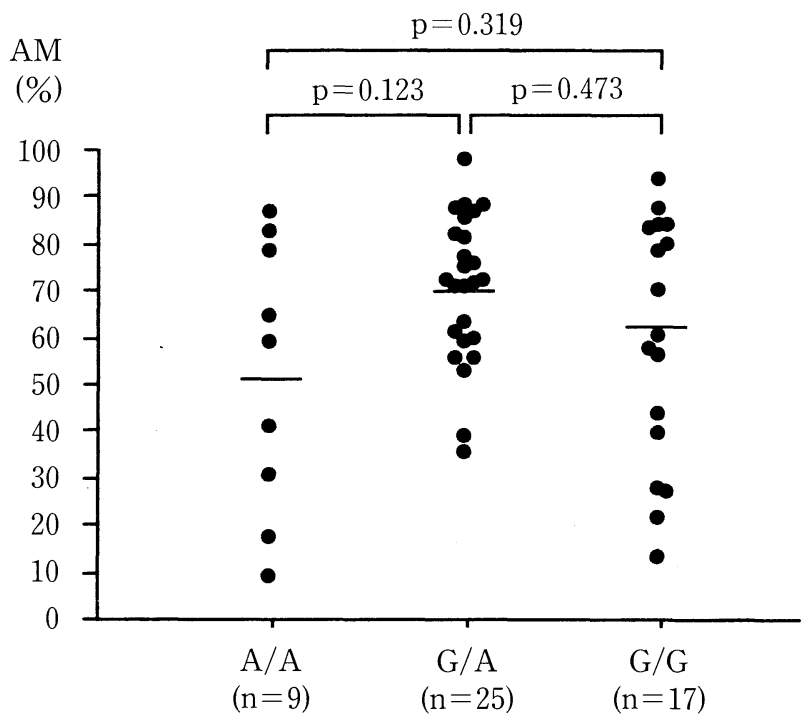

A

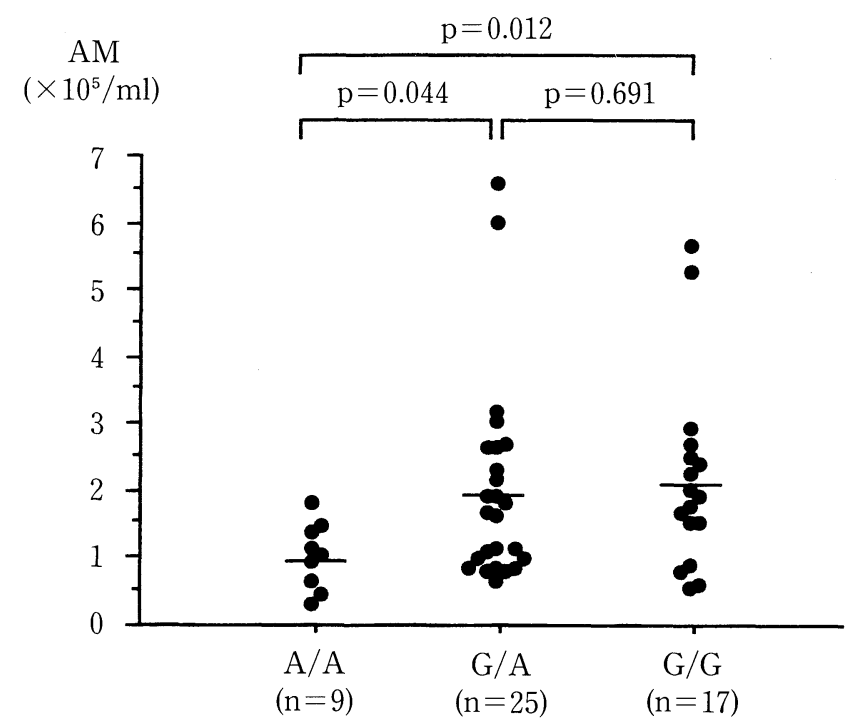

$\mathrm{B}$

Figure 2. Relationships between MCP-1 genotypes and percentages of alveolar macrophages (AMs) in BALF cells (A) and absolute counts of AMs (B) in 51 Japanese sarcoidosis cases. Means are shown as horizontal bars. The absolute counts of AMs are significantly different among the genotypes $(p=0.048)$. 


\section{Discussion}

The present study showed a SNP at position $-2,518$ of the MCP-1 gene $5^{\prime}$ flanking region and a biallelic dinucleotide microsatellite repeat polymorphism within the promoter region of the MIP-1A gene in Japanese patients with sarcoidosis. Although we found no significant difference in the genotype or allele frequency between the patients and control subjects and no relationship between the polymorphisms and the serum ACE level, organ involvement, roentgenographic stages, or deterioration in chest radiographs during the follow-up, a significant difference in the absolute counts of AMs in BALF among the genotypes for the MCP-1 gene was found. Our findings indicate that the polymorphisms do not play a substantial role in the genetic predisposition for sarcoidosis or in clinical manifestations of sarcoidosis in this Japanese population and that the MCP-1 promoter SNP might be related to the recruitment of monocytes/macrophages to alveolar spaces in sarcoidosis.

The current consensus regarding its pathogenesis is that sarcoidosis results from exposure of genetically susceptible hosts to particular environmental factors (15). Some polymorphisms have been reported to be involved in the susceptibility to sarcoidosis, in disease severity and progression, or in disease prognosis $(14,16-18)$. Up-regulated expression of MCP-1 in the affected organ of sarcoidosis has been shown $(9,19)$. MCP-1 exhibits chemotactic activity toward monocytes/macrophages and induces the production of inflammatory cytokines affecting granuloma formation. Although the SNP of MCP-1 was not associated with susceptibility to the disease, the absolute counts of AMs in BALF of the G/A and G/G genotypes were significantly increased compared with that of the A/A genotype in this sarcoidosis population. Rovin et al showed that a $\mathrm{G}$ allele at $-2,518$ affected the transcriptional activity of the distal regulatory region, and increased monocyte $\mathrm{MCP}-1$ production (11). This SNP does not alter the known transcription factor binding sites of the $\mathrm{MCP}-1$ distal regulatory region, but may affect a previously unidentified site. The $\mathrm{G}$ allele at $-2,518$ might possibly enhance the binding specificity of this motif to an unknown transcription factor resulting in an increase of the MCP-1 expression. Individuals who carry the variant A allele might have decreased recruitment of monocytes, because of low MCP-1 production. Another possible explanation for the association between the SNP and the increased AM count in BALF could be a linkage disequilibrium between this SNP and another as yet unknown functional mutation elsewhere in the MCP-1 sequence. The mechanistic details remain unclear, but our results suggest that the MCP-1 gene SNP at $-2,518$ might play an important role in the recruitment of monocytes/macrophages to the alveolar spaces in sarcoidosis. The recruitment of macrophages and $\mathrm{T}$ cells into the affected organ is thought to be an important step in the development of sarcoidosis. Further studies will be needed to elucidate whether the SNP is associated with the detailed radiographic findings or pulmonary function tests. The serum and BALF MCP-1 levels were significantly elevated in sarcoidosis patients compared with healthy controls $(9,20)$. Studies to investigate the relationship between the MCP-1 genotypes and MCP-1 levels in serum and BALF are currently underway.

We studied 145 healthy Japanese individuals and found the $\mathrm{G}$ allele/A allele ratio was $0.71 / 0.29$ in this population in contrast to $0.29 / 0.71$ in a Caucasian population in a previous report (11). The SNP in the MCP-1 promoter region was associated with the presence of cutaneous vasculitis among patients with SLE (21) and the presence and severity of asthma and increased eosinophil levels (22). However, the racial heterogeneity of the SNP in the diseases has not been examined. It has been reported that MCP-1 plays an important role in the production and development of various inflammatory diseases (2325). Further investigation of the general association of the SNP with other inflammatory diseases in Caucasians and in Asian groups is needed.

In sarcoidosis, the MIP- $1 \alpha$ level in BALF was elevated and a substantial expression of cell-associated MIP- $1 \alpha$ was detected in the macrophages including both AMs and interstitial macrophages, and interstitial pulmonary fibroblasts by immunohistochemical analysis (10). Al-Sharif et al identified a biallelic dinucleotide repeat within the promoter region of the MIP-1A gene (12). The functional significance of dinucleotide repeat regions is being increasingly realized with respect to their influence on the DNA structure, gene expression, and genomic (in)stability $(26,27)$. The present findings showed no significant difference in the MIP-1A genotype between sarcoidosis patients and healthy controls and no association between the genotype and organ involvement. The MIP- $1 \alpha$ expression from mononuclear cells is stimulated in vitro by lipopolysaccharide and IL-1 (28). The increased production of IL-1, TNF- $\alpha$ or PDGF by AMs from patients may function in an autocrine or paracrine fashion to up-regulate the expression of MIP-1 $\alpha$. Recently, novel SNPs at four sites within the MIP-1A gene and a relationship between one of the SNPs and atopic dermatitis were found in a Japanese population (29). MIP-1 $\alpha$ is involved in inflammation, wound healing and hematopoiesis $(8,30-32)$. Study of the association of the SNPs with sarcoidosis and other diseases is necessary.

Acknowledgements: The authors thank Dr. Endoh and Dr. Nakadaira of the Division of Social and Environmental Medicine for their helpful advice on the statistical analysis and Ms. Takeuchi and Ms. Ikeda for carrying out the DNA extraction.

\section{References}

1) Johns CJ, Scott PP, Schonfeld SA. Sarcoidosis. Annu Rev Med 40: 353$371,1989$.

2) Thomas PD, Hunninghake GW. Current concepts of the pathogenesis of sarcoidosis. Am Rev Respir Dis 135: 747-760, 1987.

3) Baggiolini M, Dewald B, Moser B. Interleukin- 8 and related chemotactic cytokines - CXC and CC chemokines. Adv Immunol 55: 97-179, 1994.

4) Leonard EJ, Yoshimura T. Human monocyte chemoattractant protein-1 (MCP-1). Immunol Today 11: 97-101, 1990.

5) Rollins BJ, Walz A, Baggiolini M. Recombinant human MCP-1/JE induces chemotaxis, calcium flux, and the respiratory burst in human monocytes. Blood 78: 1112-1116, 1991. 
6) Jiang Y, Beller DI, Frendl G, Graves DT. Monocyte chemoattractant protein-1 regulates adhesion molecule expression and cytokine production in human monocytes. J Immunol 148: 2423-2428, 1992.

7) Wang JM, Sherry B, Fivash MJ, Kelvin DJ, Oppenheim JJ. Human recombinant macrophage inflammatory protein-1 alpha and-beta and monocyte chemotactic and activating factor utilize common and unique receptors on human monocytes. J Immunol 150: 3022-3029, 1993.

8) Fahey TJ, Tracey KJ, Tekamp-Olson P, et al. Macrophage inflammatory protein 1 modulates macrophage function. J Immunol 148: 2764-2769, 1992.

9) Car BD, Meloni F, Luisetti M, Semenzato G, Gialdroni-Grassi G, Walz A. Elevated IL-8 and MCP-1 in the bronchoalveolar lavage fluid of patients with idiopathic pulmonary fibrosis and pulmonary sarcoidosis. Am J Respir Crit Care Med 149: 655-659, 1994.

10) Standiford TJ, Rolfe MW, Kunkel SL, et al. Macrophage inflammatory protein-1 alpha expression in interstitial lung disease. J Immunol 151: 2852-2863, 1993.

11) Rovin BH, Lu L, Saxena R. A novel polymorphism in the MCP-1 gene regulatory region that influences MCP-1 expression. Biochem Biophys Res Commun 259: 344-348, 1999.

12) Al-Sharif FM, Makki RF, Ollier WE, Hajeer AH. A new microsatellite marker within the promoter region of the MIP-1A gene. Immunogenetics 49: 740-741, 1999.

13) Ueda A, Okuda K, Ohno S, et al. NF-kappa B and Sp1 regulate transcription of the human monocyte chemoattractant protein-1 gene. J Immunol 153: 2052-2063, 1994.

14) Takada $T$, Suzuki E, Ishida $T$, et al. Polymorphism in RANTES chemokine promoter affects extent of sarcoidosis in a Japanese population. Tissue Antigens 58: 293-298, 2001.

15) Statement on sarcoidosis. Joint Statement of the American Thoracic Society (ATS), the European Respiratory Society (ERS) and the World Association of Sarcoidosis and Other Granulomatous Disorders (WASOG) adopted by the ATS Board of Directors and by the ERS Executive Committee, February 1999. Am J Respir Crit Care Med 160: 736-755, 1999.

16) Yamaguchi $E$, Itoh $A$, Hizawa N, Kawakami Y. The gene polymorphism of tumor necrosis factor-beta, but not that of tumor necrosis factor-alpha, is associated with the prognosis of sarcoidosis. Chest 119: 753-761, 2001.

17) Petrek M, Drabek J, Kolek, V et al. CC chemokine receptor gene polymorphisms in Czech patients with pulmonary sarcoidosis. Am J Respir Crit Care Med 162: 1000-1003, 2000.

18) Niimi $T$, Tomita $H$, Sato $S$, et al. Vitamin D receptor gene polymorphism in patients with sarcoidosis. Am J Respir Crit Care Med 160: 1107-1109, 1999.

19) Iyonaga K, Suga M, Ichiyasu H, Yamamoto T, Hiraga Y, Ando M. Mea- surement of serum monocyte chemoattractant protein- 1 and its clinical application for estimating the activity of granuloma formation in sarcoidosis [see comments]. Sarcoidosis Vasc Diffuse Lung Dis 15: 165-172, 1998.

20) Suga M, Iyonaga K, Ichiyasu H, Saita N, Yamasaki H, Ando M. Clinical significance of MCP-1 levels in BALF and serum in patients with interstitial lung diseases. Eur Respir J 14: 376-382, 1999.

21) Aguilar F, Gonzalez-Escribano MF, Sanchez-Roman J, Nunez-Roldan A. MCP-1 promoter polymorphism in Spanish patients with systemic lupus erythematosus. Tissue Antigens 58: 335-338, 2001.

22) Szalai C, Kozma GT, Nagy A, et al. Polymorphism in the gene regulatory region of MCP-1 is associated with asthma susceptibility and severity. $\mathbf{J}$ Allergy Clin Immunol 108: 375-381, 2001.

23) Baggiolini M, Dahinden CA. CC chemokines in allergic inflammation. Immunol Today 15: 127-133, 1994.

24) Smith RE, Strieter RM, Zhang K, et al. A role for C-C chemokines in fibrotic lung disease. J Leukoc Biol 57: 782-787, 1995.

25) Yla-Herttuala S, Lipton BA, Rosenfeld ME, et al. Expression of monocyte chemoattractant protein 1 in macrophage-rich areas of human and rabbit atherosclerotic lesions. Proc Natl Acad Sci USA 88: 5252-5256, 1991.

26) Epplen C, Santos EJ, Maueler W, van Helden P, Epplen JT. On simple repetitive DNA sequences and complex diseases. Electrophoresis 18: 1577-1585, 1997.

27) Usdin K, Grabczyk E. DNA repeat expansions and human disease. Cell Mol Life Sci 57: 914-931, 2000.

28) Standiford TJ, Kunkel SL, Liebler JM, Burdick MD, Gilbert AR, Strieter RM. Gene expression of macrophage inflammatory protein- 1 alpha from human blood monocytes and alveolar macrophages is inhibited by interleukin-4. Am J Respir Cell Mol Biol 9: 192-198, 1993.

29) Xin $X$, Nakamura $K$, Liu $H$, et al. Novel polymorphisms in human macrophage inflammatory protein-1 alpha (MIP-1alpha) gene. Genes Immun 2: 156-158, 2001.

30) Ritter LM, Bryans M, Abdo O, Sharma V, Wilkie NM. MIP1 alpha nuclear protein (MNP), a novel transcription factor expressed in hematopoietic cells that is crucial for transcription of the human MIP-1 alpha gene. Mol Cell Biol 15: 3110-3118, 1995.

31) Xu M, Sharma V, Bryans M, Wilkie NM. Identification of a new member of the MNP transcription factor family in differentiated HL60 cells. Biochem Biophys Res Commun 226: 488-494, 1996.

32) Alam R, Forsythe PA, Stafford S, Lett-Brown MA, Grant JA. Macrophage inflammatory protein-1 alpha activates basophils and mast cells. $\mathrm{J}$ Exp Med 176: 781-786, 1992. 